\title{
Guia de orientação e normas da Sociedade Brasileira de Pesquisa Odontológica (SBPqO)
}

\section{HISTÓRICO}

A SBPqO foi fundada em 05 de maio de $1983 \mathrm{em}$ São Paulo, por cinco professores, todos sócios da International Association for Dental Research (IADR): José Nicolau, Flávio Fava de Moraes, Wilson Chagas de Araújo, Roberval de Almeida Cruz e José Carlos Borges Teles (já falecido). Em 1984 foi promovida, com grande sacrifício, a primeira Reunião Anual, nos prédios do Instituto de Ciências Biomédicas da Universidade de São Paulo (ICB), com a apresentação de 54 trabalhos, divididos em duas áreas: básica e clínica. No ano seguinte (1985), em Pirassununga, no tradicional Centro de Zootecnia da Faculdade de Medicina Veterinária da USP, a Reunião Anual duplicava em pujança, com a presença de 101 trabalhos, sendo 59 apresentações orais, 38 cartazes (posters) e a instituição do Fórum Científico, com quatro trabalhos. Muito tempo passou. A SBPqO obteve sua maioridade científica durante os anos que se seguiram, graças ao seu quadro associativo de expressivo valor científico oriundo de várias regiões do Brasil, tornando-se primeiramente, seção e logo após, divisão da International Association for Dental Research (IADR). Findo o século XX, a SBPqO já se consagrara como a maior sociedade científica em pesquisa odontológica do hemisfério sul. Dentro de suas categorias associativas, entre pesquisadores, pós-graduandos e acadêmicos de Odontologia, reúne hoje, cerca de quatro mil participantes, possibilitando a presença de em torno de 3000 trabalhos científicos, nas diversas categorias de apresentação. Seus Presidentes e respectivas gestões:

- 1984/1985 - José Nicolau

- 1985/1986 - José Nicolau

- 1986/ 1987 - José Fortunato Ferreira dos Santos

- 1987/1988 - Flávio Zelante

-1988/1989 - Esther Goldenberg Birman

- 1989/1990 - Raphael Carlos Comelli Lia

- 1990/1991 - Myaki Issao

- 1991/1992 - José Nicolau

- 1992/1993 - Flávio Fava de Moraes

- 1993/1994 - Maria Fidela de Lima Navarro

- 1994/1995 - Jarbas Arruda Bauer

- 1995/ 1996 - João Humberto Antoniazzi

- 1996/1997 - Esther Goldenberg Birman

- 1997/1998 - Nelson Villa

- 1998/1999 - Edmir Matson

-1999/2000 - Sigmar de Mello Rode
- 2000/2002 - José Luiz Lage-Marques

- 2002/2004 - Fernando Ricardo Xavier da Silveira

\section{ORGANIZAÇÃO E ORGANOGRAMA}

A Sociedade Brasileira de Pesquisa Odontológica é dirigida pelos Conselhos Diretor e Consultor e pela Assembléia Geral. As eleições são realizadas, anualmente, durante o transcorrer da Reunião Anual, sendo eleitos, alternadamente, o Vice-Presidente e os quatro conselheiros e seus suplentes. A SBPqO elege o Vice-Presidente, que passa automaticamente a Presidente, findo o mandato deste.

2.1. Conselho Diretor - O Conselho Diretor, que administra e representa a Sociedade, é composto de Presidente, Vice-Presidente, ex-Presidente imediato, Secretário, Tesoureiro e Secretário Executivo (obrigatoriamente, um sócio efetivo com domicílio na sede da $\mathrm{SBPqO}$ ), todos com mandato de dois anos.

2.2. Conselho Consultor - O Conselho Consultor, que assessora e fiscaliza o Conselho Diretor, é composto por quatro membros eleitos entre os sócios efetivos, com mandato de dois anos. São eleitos, simultaneamente, dois suplentes que substituirão os membros titulares em suas faltas e impedimentos.

2.3. Assembléia Geral - Os membros sócios da SBPqO reunem-se, pelo menos uma vez ao ano, em Assembléia Geral Ordinária, durante a Reunião Anual, sendo que somente os sócios efetivos têm direito a voz e voto.

\subsection{Categorias Associativas}

2.4.1. Sócio Iniciante - Acadêmicos, estagiários ou alunos de especialização que estejam desenvolvendo projetos de pesquisa, todos sob a orientação de Sócio Efetivo, sendo que sua participação nas atividades da SBPqO far-se-á, obrigatoriamente, com a presença de seu orientador.

2.4.2. Sócio Aspirante - Alunos regularmente matriculados em curso de Mestrado ou Doutorado. Terminado o curso de pós-graduação, passarão automaticamente à categoria de Sócio Efetivo.

2.4.3. Sócio Efetivo - Pesquisadores que tenham atividade de pesquisa científica comprovada, quinquenalmente, por publicações. Não sendo atendida essa exigência, passarão automaticamente à categoria de Sócio Contribuinte. 


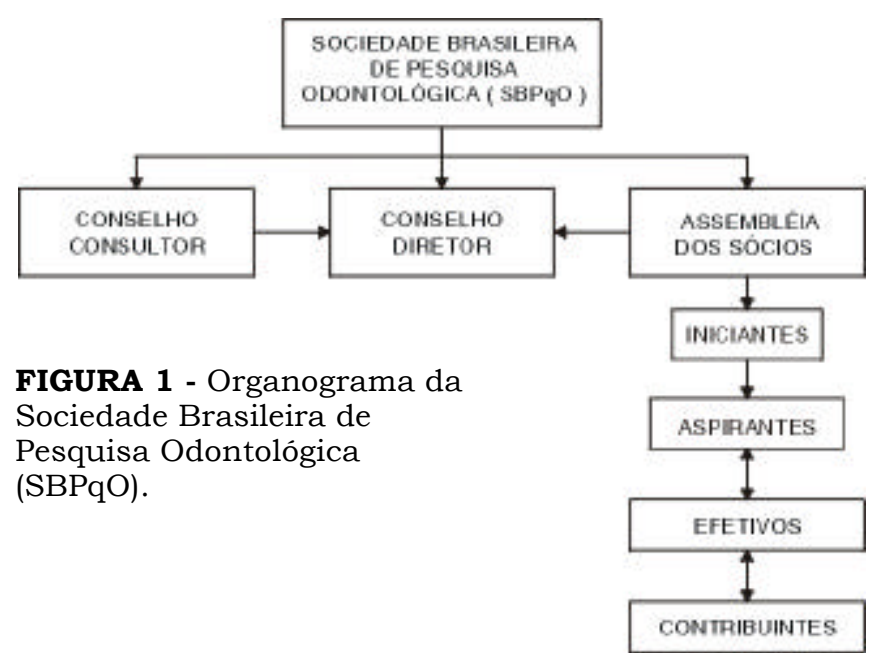

2.4.4. Sócio Contribuinte - Pessoas interessadas em pesquisa e que não se enquadrem nas categorias anteriores.

O organograma da Sociedade Brasileira de Pesquisa Odontológica está ilustrado na Figura 1.

\section{ESTATUTO}

Artigo 1- - A Sociedade Brasileira de Pesquisa Odontológica - SBPqO -, criada em 05 de maio de 1983, é sociedade civil, representativa dos pesquisadores de Odontologia e áreas afins do Brasil, de duração ilimitada, com caráter associativo, científico, cultural e social, sem fins lucrativos, cuja sede e foro fixo é a cidade de São Paulo, SP.

Parágrafo Único - A SBPqO é a Divisão Brasileira da International Association for Dental Research (IADR).

Artigo $2^{\circ}$ - A SBPqO tem como finalidade promover amplamente o desenvolvimento e a divulgação da pesquisa em todas as áreas das ciências que contribuam diretamente para o desenvolvimento da saúde bucal.

Artigo $3^{\circ}$ - Os sócios da SBPqO estão classificados nas seguintes categorias:

I. Sócio Efetivo - Pesquisadores que tenham atividade de pesquisa científica comprovada, quinquenalmente, por publicações. Não sendo atendida essa exigência, passarão automaticamente à categoria de Sócio Contribuinte.

II. Sócio Aspirante - Alunos regularmente matriculados em curso de Mestrado ou Doutorado. Terminado o curso de pós-graduação, passarão automaticamente à categoria de Sócio Efetivo.
III. Sócio Iniciante - Acadêmicos, estagiários ou alunos de especialização que estejam desenvolvendo projetos de pesquisa, todos sob a orientação de Sócio Efetivo, sendo que sua participação nas atividades da SBPqO far-se-á, obrigatoriamente, com a presença de seu orientador.

IV. Sócio Contribuinte - Pessoas interessadas em pesquisa e que não se enquadrem nas categorias anteriores.

Artigo 4- - A proposta de admissão para sócios da Sociedade deverá ser apresentada, na condição de propositores, por dois Sócios Efetivos.

Parágrafo 1․ Caberá ao Conselho Consultor apreciar a proposta, aceitando-a ou rejeitando-a e, nesse caso, com justificativa que será informada ao candidato.

Parágrafo 2ํㅡ. O secretário fará o registro correspondente no quadro associativo.

Artigo 5 - O desligamento do quadro de sócios da SBPqO será efetivado quando solicitado formalmente, pelo interessado, por escrito, dirigido ao Conselho Diretor, ou em casos de inadimplência por 3 anos consecutivos. Após o pagamento do débito, o sócio poderá ser readmitido, seguidas as exigências para as diferentes categorias.

Artigo 60 - A Sociedade Brasileira de Pesquisa Odontológica será dirigida pelos Conselhos Diretor e Consultor e pelas Assembléias Gerais, obedecendo o disposto no presente Estatuto.

Artigo $7^{\circ}$ - O Conselho Diretor, que administra e representa a Sociedade, será composto de Presidente, Vice-Presidente, ex-Presidente imediato, Secretário, Tesoureiro e Secretário Executivo, todos com mandato de dois anos.

Parágrafo $1^{\circ}$ - O Secretário Executivo deverá ser, obrigatoriamente, um Sócio Efetivo com domicílio na sede da SBPqO.

Parágrafo $2^{\circ}$ - O Conselho Diretor designará, em função das necessidades, representantes ad hoc da SBPqO para ações administrativas, estabelecendo normas de atuação.

Artigo 8- O Conselho Consultor, que assessora e fiscaliza o Conselho Diretor, é composto por quatro membros eleitos entre os Sócios Efetivos, com mandato de dois anos.

Parágrafo 1 - Serão eleitos, simultaneamente, dois suplentes que substituirão os membros titulares em suas faltas e impedimentos. 
Parágrafo 2으 - O Conselho Consultor terá as funções de apreciar as propostas para a admissão de novos sócios, analisar a prestação anual de contas da Sociedade e assessorar o Conselho Diretor em todas as suas atividades.

Artigo 90 - Votarão para membros do Conselho Diretor e do Conselho Consultor somente os Sócios Efetivos em pleno gozo de seus direitos.

Parágrafo 1ㅇ. O Conselho Diretor e o Conselho Consultor preencherão os lugares que, por qualquer motivo, tornem-se vagos durante seu período de gestão.

Parágrafo $2^{\circ}$ - Na vacância do cargo de Vice-Presidente do Conselho Diretor deverá ser realizada nova eleição, por correspondência, cabendo ao Conselho Consultor estabelecer o modus operandi para inscrição e apuração.

Artigo 10․ O quorum para as reuniões de Conselho Diretor e do Conselho Consultor será a metade mais um de seus membros.

Artigo $11^{\circ}$ - Todos os sócios, em pleno gozo de seus direitos, serão convocados, obrigatoriamente, para a Reunião Anual da SBPqO.

Parágrafo Único - Outras Reuniões Científicas poderão ser promovidas por decisão do Conselho Diretor e aprovação do Conselho Consultor.

Artigo 12 - Os membros sócios da SBPqO reunir-se-ão, pelo menos uma vez ao ano, em Assembléia Geral Ordinária, durante a Reunião Anual.

Parágrafo $1^{\circ}$ - A Ordem do Dia será distribuída a todos sócios presentes no primeiro dia da Reunião Anual.

Parágrafo 2 - Durante a Assembléia Geral Ordinária, será realizada a eleição do Vice-Presidente do Conselho Diretor, nos anos pares, e dos membros do Conselho Consultor, nos anos ímpares.

Parágrafo $3^{\circ}$ - Para o Conselho Diretor será eleito apenas o Vice-Presidente, sendo os demais membros designados pelo Presidente que toma posse, devendo ser estes referendados pela Assembléia.

Parágrafo 4- - Ao final da Assembléia Geral Ordinária, tomarão posse de seus cargos os eleitos na mesma e aqueles designados pelo Presidente do Conselho Diretor eleito.

Parágrafo 5ํ - A Assembléia Geral Ordinária iniciar-se-á, em primeira convocação, com presença de metade dos Sócios Efetivos e, em segunda convocação, 30 minutos após, com qualquer número.

Parágrafo $6^{\circ}$ - As deliberações serão sempre tomadas por maioria simples.
Artigo 13ㅇ- As Assembléias Gerais Extraordinárias poderão ser convocadas pelo Conselho Diretor ou pela maioria simples dos Sócios Efetivos. A convocação, bem como a Ordem do Dia, será enviada a todos os sócios quites com a Sociedade, com antecedência mínima de 4 semanas da data estipulada.

Parágrafo 1ํ - As Assembléias Extraordinárias efetuar-se-ão, em primeira convocação, com a presença mínima de metade dos Sócios Efetivos e, em segunda, 30 minutos após, com qualquer número.

Parágrafo $2^{\circ}$ - As deliberações serão tomadas por maioria simples, exceto no caso de dissolução da Sociedade.

Artigo 14․ - A Assembléia Geral Ordinária da Sociedade poderá adotar, alterar ou emendar regulamentos e recomendações propostas pelo Conselho Diretor, Conselho Consultor ou pela própria Assembléia.

Artigo 15- Qualquer sócio efetivo poderá propor alterações no Estatuto, desde que a proposta seja oficiada ao Secretário até 4 semanas antes da próxima Assembléia Geral Ordinária que deverá apreciar, discutir e votar a(s) alteração(ões) proposta(s). Artigo 16- Os sócios poderão ser passíveis de aplicação das seguintes penas disciplinares e sanções, a saber:

I. advertência escrita;

II. suspensão de apresentação de trabalho na Reunião Anual;

III. suspensão temporária da condição de sócio;

IV. suspensão definitiva e exclusão do quadro associativo.

Parágrafo 1- Compete ao Conselho Diretor aplicar as penas e sanções previstas nos itens I, II e III.

Parágrafo $2^{\circ}$ - Compete ao Conselho Diretor, com aprovação do Conselho Consultor, a aplicação referente ao item IV.

Parágrafo $3^{\circ}$ - Cabe recurso, junto ao Conselho Consultor, de quaisquer das penas ou sanções aplicadas e, em última instância, à Assembléia Geral Ordinária.

Artigo 17․ - Compete ao Presidente do Conselho Diretor representar a Entidade, em juízo ou fora dele, e em suas relações com terceiros.

Parágrafo Único - Os sócios não respondem individualmente pelas obrigações sociais, financeiras e jurídicas da Sociedade. 
Artigo 18으 - A Sociedade poderá ser dissolvida, em qualquer tempo, em Assembléia devidamente convocada para este fim.

Parágrafo Único - Nenhuma parte dos bens financeiros e patrimoniais da SBPqO poderá ser distribuída entre seus membros, devendo ser utilizada, obrigatoriamente, para pesquisa odontológica. $\mathrm{O}$ Conselho Diretor deverá apresentar, durante a Assembléia, os valores devidos e o valor do saldo que restará após a quitação de todos os débitos da Sociedade, cabendo à Assembléia decidir a forma de utilização deste saldo.

\section{REGULAMENTO}

\subsection{Eleição}

4.1.1. O Vice-Presidente do Conselho Diretor será eleito, nos anos pares, e o Conselho Consultor, nos anos ímpares, na Assembléia Geral Ordinária, durante a Reunião Anual da SBPqO.

4.1.2. As eleições serão realizadas na primeira parte da Assembléia, quando os Sócios Efetivos presentes depositarão a sua cédula junto à Mesa Eleitoral e a apuração será efetuada a seguir.

4.1.3. Qualquer Sócio Efetivo em pleno gozo de seus direitos poderá candidatar-se a cargos eletivos da SBPqO, mediante manifestação por escrito, até 4 meses antes do término do mandato dos cargos pleiteados.

4.1.4. O Conselho Diretor comporá uma Mesa Eleitoral com 3 (três) Sócios Efetivos, durante a Reunião Anual que terá duração determinada, fará o escrutínio e redigirá relatório com os resultados.

4.1.5. O candidato mais votado deverá alcançar, pelo menos, a maioria simples (50\% mais um) dos votos recebidos para a Vice-Presidência. Em caso de não ser alcançada maioria, os dois nomes mais votados serão submetidos a segundo escrutínio, nos moldes do item 4.1.4. Quanto à eleição dos membros do Conselho Consultor, serão indicados como titulares os 4 Sócios Efetivos mais votados e os 2 seguintes, como suplentes.

4.1.6. No caso de empate na eleição para Vice-Presidente, o primeiro critério será o do sócio mais antigo; persistindo o empate, será eleito o mais idoso.

4.1.7. O relatório preparado pela Mesa Eleitoral será lido, pelo Secretário, na Assembléia Anual Ordinária em curso e transcrito no Livro de Atas da SBPqO.
4.1.8. A secretaria deverá preparar as cédulas contendo a lista dos membros elegiveis definidos nos itens 1.1 e 1.3, bem como a lista dos Sócios Efetivos quites com a Sociedade.

4.1.9. Para efeito de regularização dos mandatos, no ano 2000, será eleito o Vice-Presidente do Conselho Diretor e, em 2001, os membros do Conselho Consultor, estendendo-se os respectivos mandatos dos atuais membros.

\subsection{Reuniões}

4.2.1. Compete ao Conselho Diretor determinar o local e a época para a realização da Reunião Anual da SBPqO, ouvida a opinião de seus sócios, durante a Assembléia Geral Ordinária.

4.2.2. A programação científica e social, bem como a estrutura da Reunião é da competência do Conselho Diretor, que designará uma Comissão Organizadora para sua concretização e operação.

4.2.3. Somente poderão participar da Reunião Anual os sócios, de todas as categorias, quites com a tesouraria incluindo-se a anuidade do ano em curso.

\subsection{Anuidades}

4.3.1. O valor das anuidades a serem pagas pelo sócio será fixado, anualmente, pelo Conselho Diretor, em reunião expressamente convocada para esse fim.

4.3.2. O sócio que deixar de pagar as anuidades por mais de um ano deixará de participar das atividades da Sociedade, podendo, entretanto, recuperar o pleno gozo de seus direitos após o pagamento das mesmas.

\subsection{Prestação de contas}

4.4.1. Dentro de 90 dias após a Assembléia Geral Ordinária, a tesouraria apresentará balancete circunstanciado, o qual será encaminhado pelo Presidente ao Conselho Consultor.

4.4.2. O Conselho Consultor preparará um parecer, após exame do balancete, que será transcrito no Livro de Atas da SBPqO e, lido pelo Tesoureiro, na Assembléia Geral Ordinária seguinte, para aprovação pelos Sócios Efetivos presentes.

4.4.3. Relação com a International Association for Dental Research (IADR) - A SBPqO é a Divisão Brasileira da International Association for Dental Research IADR.

4.5. Reunião Anual - A Reunião Anual é organizada pelo Conselho Diretor, sendo auxiliado nessa tare- 
fa por um grupo de sócios, dentre as várias categorias.

\subsubsection{Organização geral}

4.5.1.1. Comissão de Apoio - A Comissão de Apoio é constituída de membros convidados anualmente pelo Conselho Diretor e coordenada por um deles.

4.5.1.1.1. Atribuições - São atribuições da Comissão de Apoio, executar toda a logística de estruturação da Reunião Anual e apoio logístico a todas as atividades científicas realizadas durante a Reunião Anual.

4.5.1.1.2. Logística de atuação - Durante o transcorrer da Reunião Anual, a Comissão de Apoio proverá os recursos necessários para a infra-estrutura de funcionamento de todas as Comissões Julgadoras, bem como, de todas as atividades científicas oficiais. Os membros da Comissão de Apoio se reportam ao Coordenador e este, ao Conselho Diretor. Dentre as atribuições comuns da Comissão de Apoio contam: fornecimento de material impresso, roteiros, indicações de locais, avisos de modificações, monitoramento de atividades científicas.

4.5.2. Áreas de Excelência - As Áreas de Excelência compreendem sete grandes grupos, subdivididos em áreas afins, contemplando os setores em que atuam os sócios da $\mathrm{SBPqO}$, bem como as áreas de atuação da Comissão Científica Nacional:

1a - Biologia Craniofacial

$1 \mathrm{~b}$ - Cirurgia Bucomaxilofacial

1c - Ortodontia

1d - Ortopedia Funcional dos Maxilares

2a - Biologia Pulpar

2b - Terapia Endodôntica

3a - Cariologia

3b - Tecido Mineralizado

3c - Controle de Infecção

3d - Microbiologia

3e - Imunologia

3f - Fisiologia

$3 g$ - Bioquímica

3h - Nutrição

3 i - Farmacologia

4a - Ciências do Comportamento

$4 \mathrm{~b}$ - Odontopediatria

5a - Materiais Dentários

$5 b$ - Dentística

$6 a$ - Oclusão

6b-ATM 6c - Próteses

$7 \mathrm{a}$ - Estomatologia

$7 \mathrm{~b}$ - Radiologia

7c - Sistemas de Diagnóstico

$7 \mathrm{~d}$ - Odontogeriatria

7 e - Patologia Experimental

$8 \mathrm{a}$ - Implantologia

$8 \mathrm{~b}$ - Pesquisa Periodontal

\subsubsection{Normas para elaboração dos resumos}

- Título: no máximo 120 caracteres.

- Autores: separados por vírgulas; sempre dar um espaçamento entre as iniciais. No máximo 120 caracteres. Exemplo: SILVEIRA, F. R. X.*; VILLA, N; ITO, I. Y. (Atenção: sobrenome, nome e autor apresentador do trabalho identificado pelo asterisco).

- Resumo: deve conter Objetivos, Métodos e Resultados, Conclusão, Apoio Financeiro (mencionar na última linha). Os itens Objetivos, Métodos e Resultados não deverão estar explicitados no resumo sob a forma de tópicos, mas estes são itens importantes para o bom entendimento do texto científico. O item Conclusão não fará parte dos trabalhos que serão apresentados no Projeto de Pesquisa. No máximo 1.600 caracteres.

\subsubsection{Normas para elaboração dos painéis}

- Dimensões: o espaço destinado ao painel será de 1,70 m de altura por 0,90 m de largura.

- Título: deve ser o mesmo utilizado no resumo e ser escrito em letras maiúsculas. Abaixo do título e com letras menores, devem aparecer os nomes dos autores, do laboratório, do departamento, da instituição, da cidade e do estado.

- O nome do apresentador deverá estar sublinhado e acompanhado de uma foto afixada no canto superior direito.

- Corpo do painel: deve ser auto-explicativo, de preferência com o mínimo possível de texto e o máximo de ilustrações (figuras, diagramas e tabelas).

- Sugere-se que as conclusões sejam colocadas em forma de itens.

4.5.5. Normas para elaboração do Fórum Científico - O Fórum Científico é dirigido a pós-graduandos ou pós-graduados (sócios aspirantes e efetivos até um ano após recebimento do título) em Odontologia e áreas afins. Para concorrer, serão aceitos teses ou trabalhos inéditos escritos em português (A Comissão Julgadora selecionará os trabalhos para a apresentação oral com tempo de apresen- 
tação de 30 minutos, com 20 minutos para argüição). O formato dos trabalhos deverá seguir as normas estabelecidas pela revista Pesquisa Odontológica Brasileira. A concisão do texto e a precisão de linguagem serão itens de grande importância. Por essa razão, o texto, em espaço duplo, deverá limitar-se ao máximo de 20 páginas incluindo Introdução e Revisão de Literatura, Proposição, Material e Métodos, Resultados, Discussão, Conclusões e Referências Bibliográficas. Realizar a inscrição, optando pela modalidade Fórum Científico, preenchendo os dados para a inscrição do resumo que será apresentado sob a forma de painel. O texto completo em Word deverá ser anexado no ícone denominado "Trabalho completo".

4.5.6. Comissão Científica Nacional (CCN) - É o corpo de assessores da Sociedade Brasileira de Pesquisa Odontológica. Constituída de sócios efetivos recadastrados, selecionados a partir de suas Áreas de Excelência, tem a missão de avaliar os trabalhos inscritos para apresentação nas Reuniões anuais, nas diversas modalidades, bem como, atuar nas Comissões Julgadoras durante os eventos científicos promovidos pela Sociedade Brasileira de Pesquisa Odontológica.

4.5.7. Critérios de avaliação para os trabalhos inscritos - Todos os trabalhos inscritos para apresentação são avaliados, por, no mínimo 2 assessores da CCN, cujo parecer, baseado nos critérios de seleção, podem ser os seguintes:

A - Trabalho aceito

B - Trabalho aceito com ressalvas

R - Trabalho recusado

Trabalho AA - aceito para apresentação

Trabalho AB - encaminhado a um terceiro assessor

Trabalho BB - encaminhado a um terceiro assessor

Trabalho AR - encaminhado a um terceiro assessor

Trabalho BR - encaminhado a um terceiro assessor

Trabalho RR - recusado para apresentação

A avaliação deve ser baseada no elenco de critérios listados a seguir, que constituem as razões para a rejeição:

1) Assuntos pobremente organizados;

2) Informações ausentes no trabalho: Objetivos, Métodos, Resultados e Conclusões;
3) Natureza do assunto não explicitada pelo título ou pelo conteúdo do trabalho;

4) Resumo já apresentado em outros encontros ou já publicado;

5) Assunto bem explicitado, mas de importância duvidosa;

6) Critérios não muito bem definidos para a avaliação das variáveis;

7) Escolha questionável de controles;

8) Nenhum grupo de controle relatado;

9) Métodos para obter dados não apropriados em relação à proposição;

10) Confusões entre as premissas conduzindo a falsos raciocinios;

11) Conclusões não correspondem ao método de análise aplicado aos dados;

12) Vernáculo inadequado para os resumos;

13) Conclusões não suportadas pelos resultados;

14) Falta critérios de definição da amostra;

15) Falta critérios de alocamento das unidades experimentais entre os grupos de estudo;

16) Tipo de estudo;

17) Relevância do estudo;

18) Contribuição pouco relevante em relação ao estágio atual de conhecimento do assunto;

19) Conclusões não suportadas por análise estatística;

20) Metodologia inapropriada para avaliar o efeito do tratamento;

21) Delineamento inadequado de pesquisa.

A avaliação segue o fluxograma da Figura 2.

\subsubsection{Categorias de apresentação dos trabalhos}

4.5.8.1. Painel Iniciante (Prêmio Miyaki Issao)

4.5.8.1.1. Considerações gerais - Participam nessa modalidade todos os trabalhos elaborados e apresentados por Sócios Iniciantes sob orientação de Sócio Efetivo. Todos os trabalhos inscritos nessa modalidade concorrem ao Prêmio Miyaki Issao cuja seleção da Comissão Avaliadora indicará entre os sócios iniciantes apresentadores o vencedor do prêmio Miyaki Issao do ano e dois ganhadores dos diplomas de honra ao mérito.

4.5.8.1.2. Comissão Julgadora - A Comissão Julgadora do Prêmio Miyaki Issao é constituída por até onze sócios efetivos e coordenada por um 


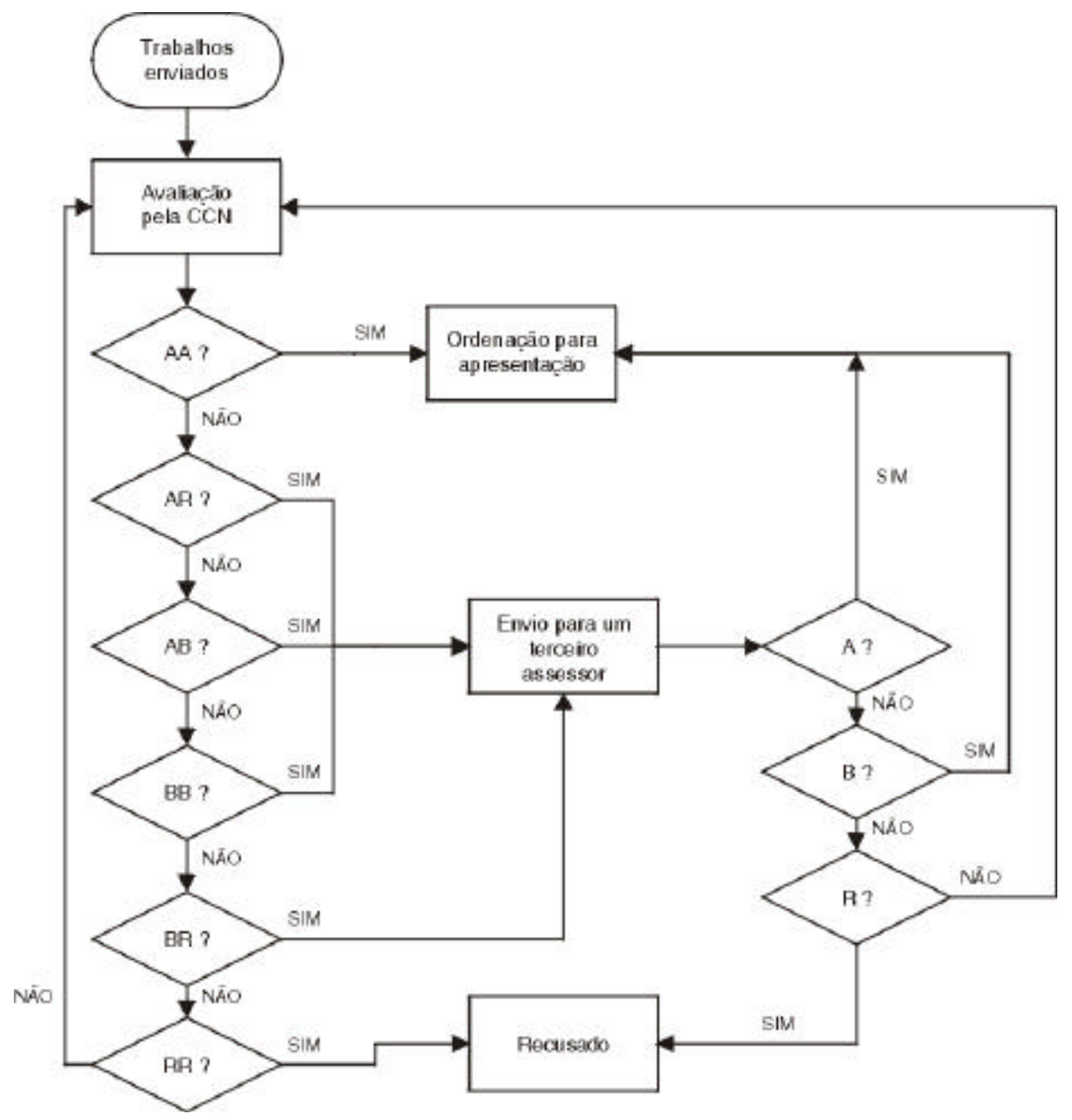

FIGURA 2 - Fluxograma de avaliação dos trabalhos inscritos pela CCN. deles, podendo ser reconduzidos anualmente, mediante convite formal do Conselho Diretor.

4.5.8.1.3. Critérios para avaliação de Painel Iniciante - Os critérios para avaliação são os mesmos relativos à avaliação de painéis, levando-se aqui, em conta, tratar-se de trabalhos desenvolvidos por Sócio Iniciante, sob orientação de Sócio Efetivo.

4.5.8.1.4. Documentação utilizada - A documentação a ser utilizada inclui prancheta, caneta e formulário específico para a avaliação de painéis relativos ao Prêmio Miyaki Issao.

\subsection{Cronograma dentro da Reunião Anual}

a) Reunião da Comissão Julgadora com o Conselho Diretor e Comissão de Apoio.

b) Reunião da Comissão Julgadora para distribuição de tarefas e modus operandi.

c) Avaliação das sessões de Painéis de Iniciantes. d) Reunião da Comissão Julgadora para definição dos ganhadores.

e) Entrega dos resultados e relatório final pelo Presidente ao Conselho Diretor.

\subsubsection{Painel Aspirante (Prêmio Painel Aspirante)}

4.5.8.2.1. Considerações gerais - Participam nessa modalidade todos os trabalhos elaborados e apresentados pelos Sócios Aspirantes.

4.5.8.2.2. Comissão Julgadora - Constituída por número de Sócios Efetivos recadastrados a ser definido pelo Conselho Diretor, em função do número de painéis inscritos aceitos para apresentação em cada Reunião Anual. Dessa Comissão Julgadora são escolhidos os Coordenadores de reuniões de Grupos de Painéis, em cada Área de Excelência.

4.5.8.2.3. Critérios para avaliação de Painel Aspirante Os critérios para avaliação são os mesmos relativos à avaliação de painéis, levando-se, aqui, em conta tratar-se de trabalhos desen- 
volvidos por Sócio Aspirante, sob orientação de Sócio Efetivo.

4.5.8.2.4. Documentação utilizada - A documentação a ser utilizada inclui prancheta, caneta e formulário específico para a avaliação de painéis relativos à categoria Painel Aspirante.

\subsection{Cronograma dentro da Reunião Anual}

a) Reunião da Comissão Julgadora com o Conselho Diretor e Comissão de Apoio.

b) Reunião da Comissão Julgadora para distribuição de tarefas e modus operandi.

c) Avaliação das sessões de Painéis de Aspirantes.

d) Reunião da Comissão Julgadora para definição dos ganhadores.

e) Entrega dos resultados e relatório final pelo Coordenador ao Conselho Diretor.

\subsubsection{Painel Efetivo (Prêmio Painel Efetivo)}

4.5.8.3.1. Considerações gerais - Participam nessa modalidade todos os trabalhos elaborados e apresentados pelos Sócios Efetivos.

4.5.8.3.2. Comissão Julgadora - Constituída por número de Sócios Efetivos recadastrados a ser definido pelo Conselho Diretor, em função do número de painéis inscritos aceitos para apresentação em cada Reunião Anual. Dessa Comissão Julgadora são escolhidos os Coordenadores de reuniões de Grupos de Painéis, em cada Área de Excelência.

4.5.8.3.3. Critérios para avaliação - Os critérios para avaliação são os mesmos relativos à avaliação de painéis, levando-se, aqui, em conta tratar-se de trabalhos desenvolvidos por Sócio Efetivo.

4.5.8.3.4. Documentação utilizada - A documentação a ser utilizada inclui prancheta, caneta e formulário específico para a avaliação de painéis relativos à categoria Painel Efetivo.

\subsection{Cronograma dentro da Reunião Anual}

a) Reunião da Comissão Julgadora com o Conselho Diretor e Comissão de Apoio.

b) Reunião da Comissão Julgadora para distribuição de tarefas e modus operandi.

c) Avaliação das sessões de painéis de Efetivos.

d) Reunião da Comissão Julgadora para definição dos ganhadores.

e) Entrega dos resultados e relatório final pelo Coordenador ao Conselho Diretor.

\subsubsection{Prêmio Edward E. Hatton}

4.5.8.4.1. Considerações gerais - Essa modalidade destina-se a jovens pesquisadores com potencial para o desenvolvimento de pesquisa em Odontologia. Os que desejarem concorrer ao "Hatton Awards Competition" deverão apresentar seus trabalhos sob a forma de painel de acordo com o padrão divulgado. A seleção nacional, durante a Reunião Anual da Sociedade Brasileira de Pesquisa Odontológica exige, assim como a Internacional Association for Dental Research, a apresentação do assunto sob forma verbal e em inglês durante cinco minutos seguidos de argüição pelos julgadores. Os dois trabalhos classificados deverão ser apresentados na Reunião Anual da IADR no ano seguinte (o domínio do idioma inglês é fundamental para o bom desempenho do candidato). Os vencedores se comprometem a representar a Divisão Brasileira no Congresso da IADR no ano seguinte, sendo este um requisito obrigatório para a homologação dos vencedores.

4.5.8.4.2 Comissão Julgadora - A Comissão Julgadora do Prêmio Edward E. Hatton, será constituída por três membros, selecionados pelo Conselho Diretor, entre os Sócios Efetivos Doutores recadastrados, com domínio da lingua inglesa, sendo coordenada por um dos membros.

4.5.8.4.3. Critérios para avaliação - A pontuação dos quesitos analisados será distribuída da seguinte forma: $20 \%$ destinada ao texto; $40 \%$ ao desempenho nas perguntas e respostas; $40 \%$ para a apresentação verbal. O painel deverá estar impresso em inglês bem como a apresentação oral será em inglês. Lembrar que a apresentação do assunto é sob forma verbal e em inglês durante 5 minutos.

4.5.8.4.4. Documentação utilizada - A documentação a ser utilizada inclui prancheta, caneta e formulário específico para a avaliação de painéis relativos à categoria Prêmio Edward E. Hatton.

\subsection{Cronograma dentro da Reunião Anual}

a) Reunião da Comissão Julgadora com o Conselho Diretor e Comissão de Apoio.

b) Reunião da Comissão Julgadora para distribuição de tarefas e modus operandi.

c) Avaliação dos painéis e classificação dos finalistas para apresentação. 
d) Avaliação dos finalistas.

e) Reunião da Comissão Julgadora para definição dos ganhadores.

f) Entrega dos resultados e relatório final pelo Coordenador ao Conselho Diretor.

\subsubsection{Fórum Científico}

4.5.8.5.1. Considerações gerais - O Fórum Científico é dirigido a pós-graduandos ou pós-graduados (sócios aspirantes e efetivos até um ano após recebimento do título) em Odontologia e áreas afins. Para concorrer, serão aceitos teses ou trabalhos inéditos escritos em português. O formato dos trabalhos deverá seguir as normas estabelecidas pela revista Pesquisa Odontológica Brasileira. A concisão do texto e a precisão de linguagem serão itens de grande importância. Por essa razão, o texto, em espaço duplo, deverá limitar-se ao máximo de 20 páginas incluindo Introdução e Revisão de Literatura, Proposição, Material e Métodos, Resultados, Discussão, Conclusões e Referências Bibliográficas. Realizar a inscrição, optando pela modalidade Fórum Científico, preenchendo os dados para a inscrição do resumo que será apresentado sob a forma de painel. O texto completo em Word deverá ser anexado no ícone denominado "Trabalho completo".

4.5.8.5.2. Comissão Julgadora - A Comissão Julgadora do Prêmio Fórum Científico, será constituída por três membros, selecionados pelo Conselho Diretor, entre os Sócios Efetivos Doutores recadastrados, sendo coordenada por um dos membros.

4.5.8.5.3. Critérios para avaliação - A Comissão Julgadora selecionará os trabalhos para a apresentação oral com tempo de apresentação de 30 minutos, com 20 minutos para argüição. Os critérios para avaliação seguem as normas de avaliação para publicação de um trabalho científico na revista Pesquisa Odontológica Brasileira, acrescidos de aspectos avaliados durante o desempenho do candidato em sua apresentação e argüição.

4.5.8.5.4. Documentação utilizada - A documentação a ser utilizada inclui prancheta, caneta e formulário específico para a avaliação de trabalhos relativos à categoria Prêmio Fórum Científico.

4.5.8.5.5. Cronograma prévio à Reunião Anual - Avaliação dos trabalhos e classificação dos finalistas para apresentação, previamente à Reunião Anual.

\subsection{Cronograma durante a Reunião Anual}

a) Reunião da Comissão Julgadora com o Conselho Diretor e Comissão de Apoio.

b) Reunião da Comissão Julgadora para distribuição de tarefas e modus operandi.

c) Avaliação dos finalistas.

d) Reunião da Comissão Julgadora para definição dos ganhadores.

e) Entrega dos resultados e relatório final pelo Coordenador ao Conselho Diretor.

\subsubsection{Pesquisa Odontológica de Ação Coletiva (POAC)}

4.5.8.6.1. Considerações gerais - Destinam-se a essa modalidade trabalhos apresentados, sob a forma de painel, por sócios de todas as categorias, que efetivamente possam produzir benefícios e que apresentem relevância social com reflexo na qualidade de vida da população.

4.5.8.6.2. Comissão Julgadora - A Comissão Julgadora do Prêmio POAC, será constituída por três membros, selecionados pelo Conselho Diretor, entre os Sócios Efetivos Doutores recadastrados, sendo coordenada por um dos membros.

4.5.8.6.3. Critérios para avaliação - Os critérios para avaliação, são os mesmos relativos à avaliação de painéis, levando-se aqui, em conta, tratar-se de trabalhos cujos resultados possam produzir beneficios à dada comunidade e que apresentem nitidamente possibilidades de melhoria de qualidade de vida da população ou comunidade envolvida.

4.5.8.6.4. Documentação utilizada - A documentação a ser utilizada inclui prancheta, caneta e formulário específico para a avaliação de trabalhos relativos à categoria Prêmio Pesquisa Odontológica de Ação Coletiva (POAC).

\subsection{Cronograma dentro da Reunião Anual}

a) Reunião da Comissão Julgadora com o Conselho Diretor e Comissão de Apoio.

b) Reunião da Comissão Julgadora para distribuição de tarefas e modus operandi.

c) Avaliação dos painéis.

d) Reunião da Comissão Julgadora para definição dos ganhadores.

e) Entrega dos resultados e relatório final pelo Coordenador ao Conselho Diretor.

\subsubsection{Pesquisa-Ensino}


4.5.8.7.1. Considerações gerais - Os participantes podem pertencer a todas as categorias e seus trabalhos, sob a forma de painel, devem estar vinculados aos métodos, estratégias, avaliações, simuladores, etc., visando aprimorar o ensino odontológico e áreas afins em seus diferentes niveis.

4.5.8.7.2. Comissão Julgadora - A Comissão Julgadora do Prêmio Pesquisa-Ensino, será constituída por três membros, selecionados pelo Conselho Diretor, entre os Sócios Efetivos Doutores recadastrados, sendo coordenada por um dos membros.

4.5.8.7.3. Critérios para avaliação - Os critérios para avaliação, são os mesmos relativos à avaliação de painéis, levando-se, aqui, em conta tratar-se de trabalhos cujos resultados possam produzir benefícios e inovações ao ensino odontológico em todos os seus niveis, mas notadamente no de graduação.

4.5.8.7.4. Documentação utilizada - A documentação a ser utilizada inclui prancheta, caneta e formulário específico para a avaliação de trabalhos relativos à categoria Prêmio Pesquisa-Ensino.

\subsection{Cronograma dentro da Reunião Anual}

a) Reunião da Comissão Julgadora com o Conselho Diretor e Comissão de Apoio.

b) Reunião da Comissão Julgadora para distribuição de tarefas e modus operandi.

c) Avaliação dos painéis.

d) Reunião da Comissão Julgadora para definição dos ganhadores.

e) Entrega dos resultados e relatório final pelo Coordenador ao Conselho Diretor.

\subsubsection{Atividades durante a Reunião Anual}

4.5.8.8.1. Instalação da Secretaria - A instalação da Secretaria da Reunião Anual da Sociedade Brasileira de Pesquisa Odontológica se fará sempre na manhã do primeiro dia de atividades, incluindo aquelas da Pré-Reunião (Cursos, Simpósios ou outras atividades previamente programadas). A instalação da Secretaria será de responsabilidade da empresa contratada pelo Conselho Diretor para tal fim. Compreende a implementação de toda a infra-estrutura para atender aos requisitos de entrega de material, efetuação de novas inscrições, pagamentos, e todas as atividades de orientação aos participantes inscritos, no que tange aos serviços de secretaria.

4.5.8.8.2. Atividade Pré-Reunião - A atividade Pré-Reunião é uma atividade facultativa, podendo ou não, ser implementada pelo Conselho Diretor, podendo envolver a realização de cursos de rápida duração, palestras, simpósios e outras atividades correlatas, previamente marcadas e para as quais haja inscrição prévia. Ocorrerá sempre um dia antes da cerimônia oficial de abertura da Reunião Anual.

4.5.8.8.3. Reunião preliminar de orientação às Comissões Julgadoras - Será sempre realizada no dia da abertura da Reunião Anual, com a participação das Comissões Julgadoras das diversas categorias, Conselho Diretor e Comissão de Apoio (CA). Seu objetivo é o de repassar com os membros das Comissões Julgadoras os critérios a serem utilizados, a infra-estrutura de apoio disponivel e dirimir dúvidas, bem como apresentar participantes substitutos (nos casos de impedimentos dos membros convidados).

4.5.8.8.4. Reunião de Grupos - A reunião de grupo de painéis na $\mathrm{SBPqO}$ é um diferencial das atividades de apresentação de trabalhos científicos. Trata-se de um momento que reúne os autores das mais diferentes instituições e favorece uma discussão descontraída sobre objetivos, metodologias, resultados e conclusões. É de fundamental importância a participação dos autores nessa atividade.

A Comissão Avaliadora poderá solicitar uma nova apresentação para complementar, nessa ocasião, sua avaliação e melhor selecionar os trabalhos vencedores de cada grupo de área. Serão selecionados os três melhores trabalhos de cada grupo que receberão os diplomas de menção honrosa e farão parte da galeria da SBPqO 2002.

4.5.8.8.5. Sessão de Projetos - A Sessão Oral de "Projetos" abre um espaço para a discussão e troca de idéias visando beneficiar e colaborar com os projetos de pesquisa em andamento. Sendo assim, se o interessado estiver desenvolvendo um projeto de pesquisa e encontrando dificuldades quanto à metodologia, controles, entre outras, essa atividade poderá auxiliá-lo. Para tanto, o interessado disporá de quinze minutos para discutir, em ambiente informal, sua proposta de trabalho com uma equipe de pesquisadores qualificados. Não se- 
rão disponibilizados recursos audiovisuais. Aos autores sugere-se a apresentação de textos, fotografias e documentos que subsidiem a explanação.

4.5.8.8.6. Consultório Científico - Constitui-se em atividade instituída para sanar dúvidas relacionadas às instituições de fomento à pesquisa (CAPES, FINEP, CNPq), entidades associativas, edição e publicação de periódicos, Pesquisa Odontológica Brasileira, entre outros. Em ambiente de informalidade será possível realizar contatos diretos com os responsáveis de área dessas instituições. O agendamento é feito "on line" previamente à Reunião Anual, bastando selecionar o assunto de interesse e o horário, indicando o número de inscrição à Reunião Anual.

4.5.8.8.7. Eleições - A Sociedade Brasileira de Pesquisa Odontológica elege o Vice-Presidente e os membros do Conselho Consultor, em eleição direta com voto secreto, realizada durante a Reunião Anual.

4.5.8.8.7.1. Instalação da Comissão Eleitoral - A Comissão Eleitoral é formada por três sócios efetivos recadastrados, convidados pelo Conselho Diretor, sendo instalada como parte inicial da Assembléia Geral Ordinária.
4.5.8.8.7.2. Eleição para o cargo de Vice-Presidente do Conselho Diretor - É realizada durante a Reunião Anual, nos anos pares.

4.5.8.8.7.3. Eleição para os membros do Conselho Consultor - É realizada durante a Reunião Anual, nos anos impares.

4.5.8.8.8. Assembléia Geral dos Sócios - É realizada no penúltimo dia da Reunião Anual, com a presença dos sócios, sendo presidida pelo Conselho Diretor, na pessoa do Presidente.

4.5.8.8.9. Sessão de Premiação - A Sessão de Premiação é um grande momento repleto de emoção e alegria dos grupos de pesquisa e instituições presentes nas Reuniões Anuais. Os trabalhos que se destacaram durante a Reunião, nas diversas modalidades, são divulgados às 12:00 horas do último dia da Reunião Anual, em ambiente de festa e descontração. A presença dos inscritos na Sessão de Premiação é imprescindivel para o brilhantismo das atividades.

4.5.8.8.10. Encerramento solene da Reunião Anual da SBPqO - Após a sessão de premiação, dá-se o encerramento oficial da Reunião Anual da Sociedade Brasileira de Pesquisa Odontológica pelo Presidente do Conselho Diretor.

Organizadores: Fernando Ricardo Xavier da Silveira José Luiz Lage-Marques 